\title{
Efficacy of Sunitinib Rechallenge in Kidney Cancer: Are mTOR Inhibitors Involved or Is It Only a Matter of Time?
}

\author{
Carlo Buonerba Giuseppe Di Lorenzo \\ Department of Endocrinology and Medical Oncology, Genitourinary Cancer Section, University Federico II, Naples, Italy
}

The multiple and diversifying targeted therapy-based treatment options presently available for advanced kidney cancer [1] draw a therapeutic scenario which is completely different from that of a decade ago, when cytokine-based therapy was able to provide limited results in terms of progression-free survival and response rate [2]. Agents approved for the treatment of kidney cancer in Europe, in the US and in other countries worldwide include sunitinib, sorafenib and pazopanib, three molecules inhibiting the vascular endothelial growth factor (VEGF) tyrosine kinase receptor (TKR); bevacizumab, an anti-VEGF monoclonal antibody; and everolimus and temsirolimus, two mammalian target of rapamycin (mTOR) inhibitors. As first-line treatment, bevacizumab plus interferon and sunitinib are recommended for good- and intermediate-risk patients, whereas temsirolimus is recommended for poor-risk patients. As second-line treatment, sorafenib is indicated after progression on interferon, and everolimus is recommended after progression on sorafenib or sunitinib. Pazopanib is approved for first-line treatment and for second-line treatment after progression with interferon $[3]$.

The great challenge posed by the variety of these agents is the definition of their optimal sequence of administration. In fact, approval of these agents in specific subsets of patients with metastatic renal cell cancer (mRCC) merely reflects the populations these drugs were tested in, and it was not based on comparative trials between biological agents, which were all tested against interferon alfa in the first-line setting or placebo in the second-line setting.

Temsirolimus is an emblematic example: should everolimus have been tested in its stead, it would probably also have been approved in this setting. The situation is further complicated by emerging data indicating the feasibility of re-treatment of patients with one biological agent that has been used in a previous line of therapy. In this issue of ONKOLOGIE, Grünwald et al. [4] provide retrospective data of extreme interest about efficacy of third-line sunitinib after first linesunitinib and second-line therapy with an mTOR inhibitor. In a small sample of 13 patients treated at 2 German institutions, a progression free survival (PFS) of 6.9 months and a response rate of $15 \%$ were reported. Both of these results are about 2-3 times lower than the PFS and the response rate obtained in the same sample treated with first-line sunitinib, but are in line with those obtained in another similar retrospective study conducted in $23 \mathrm{mRCC}$ patients rechallenged with sunitinib after first-line sunitinib and different kinds of subsequent treatments, which showed a response rate of $22 \%$ and a median PFS of 7.2 months [5]. We conducted a similar retrospective study in 34 patients treated with first-line sunitinib, second-line mTOR inhibitor and third-line sorafenib and obtained a median PFS of 4 months and a response rate of $23.5 \%$ [6]. Similarities and differences between these three studies are interesting. All of these studies show the feasibility of re-treatment with a VEGF TKR inhibitor, either with the very same agent employed in the first line, that is to say sunitinib, or with another agent, that is to say sorafenib. While two of these studies $[4,6]$ selected a homogenous population receiving the specific sequence TKI inhibitor - mTOR inhibitor - TKI inhibitor, the other did not, as a variety of different treatments were administered before rechallenge, including VEGF inhibitors, mTOR inhibitors, combination of VEGF inhibitors and mTOR inhibitors, or other systemic agents [5].

This raises the following question: does the efficacy of rechallenge with VEGF TKR inhibitors depend on the particular second-line treatment administered (e.g. everolimus) or does it simply require a sufficiently large timeframe between the first administration and subsequent rechallenge? We hypothesized that mTOR inhibitors could revert resistance to VEGF-TKR inhibitors [6], as resistance to everolimus and temsirolimus can be mediated by a compensatory increase in hypoxia inducible factor, which may be targeted by VEGF blocking agents [7]. A different model hypothesizes the existence of two different subpopulations of kidney cancer cells that differentiate in patients treated with sunitinib: one of fast-growing, sunitinib-sensitive cells, which are responsible for the initial response, the other of slow-growing, sunitinib-

\section{KARGER}

Fax +497614520714

Information@Karger.de

www.karger.com (c) 2011 S. Karger GmbH, Freiburg

0378-584X/11/0346-0295\$38.00/0

Accessible online at:

www.karger.com/onk
Giuseppe Di Lorenzo, MD, PhD

Department of Endocrinology and Medical Oncology

Genitourinary Cancer Section, University Federico II

Via Pansini 5, 80131 Napoli, Italy

Tel. +39 081-7463660, Fax -2203147

giuseppedilorenzoncol@hotmail.com 
refractory cells, which eventually mediate progression. At re-exposure, occurring after a sufficiently large time-frame, the impaired growth of sunitinib-sensitive cells outweighs the replication of sunitinib-refractory cells and results in disease stabilization, which is maintained for a clinically meaningful period of time. This model is speculative, but explains the low response rate and the satisfactorily long PFS recorded for sunitinib in this setting, as well as the better outcome reported for patients with a longer than 6 month interval between sunitinib treatments (median PFS, 16.5 vs. 6.0 months; logrank test, $\mathrm{p}=0.03)[5]$.

In conclusion, targeted therapy in kidney cancer poses great challenges both in the clinical and in the research setting, both in terms of optimal sequence of administration and in terms of management of side effects [8]. In other solid malignancies, such ovarian cancer [9] and prostate cancer [1012], retreatment with the same agent has been successful for patients who had discontinued treatment for reasons other than progression, but had not shown disease progression during treatment administration. The concept that in RCC the resistance might be mediated by transient mechanisms (for example variations in tumor genetic expression) that are dependent on drug exposure and can be simply reverted by treatment with a different agent for a sufficiently long time is extremely appealing and requires both pre-clinical and clinical investigations.

\section{References}

1 Di Lorenzo G, Autorino R, Sternberg CN: Metastatic renal cell carcinoma: recent advances in the targeted therapy era. Eur Urol 2009;56:959-71.

- 2 Negrier S, Escudier B, Lasset C, Douillard JY, Savary J, Chevreau C, Ravaud A, Mercatello A, Peny J, Mousseau M, Philip T, Tursz T: Recombinant human interleukin-2, recombinant human interferon alfa-2a, or both in metastatic renal-cell carcinoma. Groupe Français d'Immunothérapie. N Engl J Med 1998;338(18):1272-8.

$\checkmark 3 \mathrm{Di}$ Lorenzo G, Buonerba C, Biglietto M, Scognamiglio F, Chiurazzi B, Riccardi F, Cartenì G: The therapy of kidney cancer with biomolecular drugs. Cancer Treat Rev 2010; 36:S16-20.

4 Grünwald V, Weikert S, Seidel C, Busch J, Johannsen A, Fenner M, Reuter C, Ganser A, Johannsen M: Efficacy of sunitinib re-exposure after failure of an mTOR inhibitor in patients with metastatic RCC. Onkologie 2011;34: DOI: 10.1159/000328575.
5 Zama IN, Hutson TE, Elson P, Cleary JM, Choueiri TK, Heng DY, Ramaiya N, Michaelson MD, Garcia JA, Knox JJ, Escudier B, Rini BI: Sunitinib rechallenge in metastatic renal cell carcinoma patients. Cancer 2010;116:5400-6.

6 Di Lorenzo G, Buonerba C, Federico P, Rescigno P, Milella M, Ortega C, Aieta M, D'Aniello C, Longo N, Felici A, Ruggeri EM, Palmieri G, Imbimbo C, Aglietta M, De Placido S, Mirone V: Third-line sorafenib after sequential therapy with sunitinib and mTOR inhibitors in metastatic renal cell carcinoma. Eur Urol 2010;58:906-11.

$\checkmark 7$ Rini BI: New strategies in kidney cancer: therapeutic advances through understanding the molecular basis of response and resistance. Clin Cancer Res 2010;16:1348-54.

8 Di Lorenzo G, Porta C, Bellmunt J, Sternberg C, Kirkali Z, Staehler M, Joniau S, Montorsi F, Buonerba C: Toxicities of targeted therapy and their management in kidney cancer. Eur Urol 2011;59:526-40.
9 Gore ME, Fryatt I, Wiltshaw E, Dawson T: Treatment of relapsed carcinoma of the ovary with cisplatin or carboplatin following initial treatment with these compounds. Gynecol Oncol 1990; 36:207-11.

10 Di Lorenzo G, Buonerba C, Autorino R, De Placido S, Sternberg CN: Castration-resistant prostate cancer: current and emerging treatment strategies. Drugs 2010;70:983-1000.

11 Buonerba C, Palmieri G, Di Lorenzo G: Docetaxel rechallenge in castration-resistant prostate cancer: scientific legitimacy of common clinical practice. Eur Urol 2010;58:636-7.

12 Di Lorenzo G, Buonerba C, Faiella A, Rescigno P, Rizzo M, Autorino R, Perdonà S, Riccardi N, Scagliorini S, Scognamiglio F, Masala D, Ferro M, Palmieri G, Aieta M, Marinelli A, Altieri V, De Placido S, Cartenì G: Phase II study of docetaxel re-treatment in docetaxel-pretreated castration-resistant prostate cancer. BJU Int 2011;107:234-9. 